\title{
Study on the TIG Welding Technology of the Aluminized Steel
}

\author{
Bixin Guo ${ }^{1, a}$, Xiaowei Du ${ }^{1, b}$ \\ ${ }^{1} 118$ mail box, The First Aeronautic Institute of Air Force, Xinyang city,Henan Prov.464000 \\ agbxssw@163.com, ,gbxssw@126.com
}

Keywords: Aluminized steel; TIG welding; Technology; Welding joint

\begin{abstract}
The welding property of the Aluminized steel is analyzed in this article, TIG welding technology of Aluminized steel is presented on the base of mass experimentations, it proves that this technology can effectively prevent the welding crack and improve the property of the weld joint.
\end{abstract}

\section{Introduction}

Aluminized steel is a new type composite steel material which has been penetrated by $0.10 \sim 0.5 \mathrm{~mm}$ aluminum on its surface. [1] The material's surface is comprised of a compact thin film of Al2o3, which has high melting point. The junction of interior material and the base material is ferroaluminium structure. So aluminized steel has excellent oxidation resistance property under high temperature and very good $\mathrm{H} 2 \mathrm{~S}$, SO2, SO3 resistance property and anti-friction property, and has been utilized in petroleum, chemical and aeronautical industries. In practice, we often encounter the welding difficulty of aluminized steel pipe and flange plate ( the pipe is made of Cr5Mo aluminized steel, and the flange plate is made of 45 steel which has been aluminized.). When arc welding is adopted, crack could be found in the adjacent of the welding joint, and also the corrosion resistance of that part would drop down. The welding joint type is shown in Fig 1. After repeated tests, we adopted TIG welding technology, and got satisfactory result.

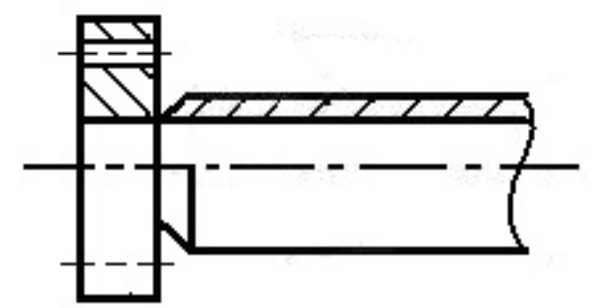

Fig.1 The structure of the welding joint

\section{Weldability analysis}

Both the inner surface and the outer surface of the Cr5Mo aluminized steel pipe have a 0.12 0.16 mm penetrated layer, which has 20\% 40\% Al, and mainly made of Al-Fe compound. From the surface to the inner part, the compounds have the order: $\mathrm{Al}_{2} \mathrm{O}_{3} \quad \mathrm{FeAl}_{3} \quad \mathrm{Fe}_{2} \mathrm{Al}_{5}$ $\rightarrow \mathrm{FeAl}_{2} \rightarrow \mathrm{Fe}_{3} \mathrm{Al}^{[2]}$. And because aluminium has active chemical property, the penetrated aluminium layer has very different structure, chemical property, melting point and thermal conductivity with the base material, if we adopt arc welding technology, some below questions will be easily found.

Welding joint crack. The aluminized steel, after welding, can easily produce crack in the welding joint area and melting zone. It has two reasons, one is that the aluminium is a ferritized element, low-melting eutecticum can be produced in the welding joint and melting zone when welding; the other reason is that the plasticity and tenacity of the welding joint and melting zone decrease, which makes the crack easily happen.

Corrosion resistance of the melting zone decrease. Lack of fusion in the welding joint, or low aluminium in the adjacent of melting zone will easily reduce the corrosion resistance of the aluminized steel welding joint, affect the lifespan of the aluminized steel structure. If the welding 
rod or wire is made from stainless steel, the property of the welding joint could match the aluminized steel, but the junction of the welding joint and base material, or the melting line, is still carbon steel, which has low corrosion resistance and oxidation resistance. The result of the experiment is shown in Table 1.

Table 1 Corrosion test result of the welding joint

\begin{tabular}{|c|c|c|c|c|c|}
\hline \multirow{2}{*}{$\begin{array}{l}\text { Welding } \\
\text { rod }\end{array}$} & \multicolumn{2}{|c|}{ Welding joint zone } & \multicolumn{2}{|c|}{ corrosion status } & \multirow[b]{2}{*}{ corrodent } \\
\hline & Welding joint & Melting line & $\begin{array}{c}\text { Welding } \\
\text { joint }\end{array}$ & Melting line & \\
\hline A312 & $\begin{array}{c}\text { A312 stainless } \\
\text { steel }\end{array}$ & $\begin{array}{c}\text { Carbon steel + } \\
\text { stainless steel } \\
\end{array}$ & $\begin{array}{c}\text { No } \\
\text { corrosion } \\
\end{array}$ & corrosion & \multirow{2}{*}{$\begin{array}{c}10 \% \sim 30 \% \\
\text { HN O3 }\end{array}$} \\
\hline $\mathrm{J} 427$ & J427 carbon steel & Carbon steel & $\begin{array}{c}\text { Heavy } \\
\text { corrosion }\end{array}$ & $\begin{array}{c}\text { Heavy } \\
\text { corrosion } \\
\end{array}$ & \\
\hline
\end{tabular}

Decrease of aluminium element at the back of the welding joint ( inner surface). Because of the high temperature of welding, the aluminium element in the penetrated layer is oxidized and burned, and cannot be re-treat by spraying or other methods. This will decrease the heat resistance and corrosion resistance of the inner surface of the pipe.

In order to deal with the above problems in the welding process of aluminized steel, the methods below can be adopted:

(1) Get rid of the aluminized layer of the joints before welding, and spray a layer of aluminium on the surface of the welding zone.

(2) Choose the filling material which has good plasticity and tenacity, especially high anti-cracking ability (for example, stainless steel welding wire or special welding rod).

(3) Adopt small welding input or proper technological methods to reduce the decrease of aluminium in the melting zone.

(4) Choose the welding methods which have intensive energy density to reduce the area of welding affecting zone and welding stress. For example TIG welding and PAW welding.

\section{TIG welding technology}

Welding material. Choose A312SL aluminized steel welding rod, with the diameter of $3.2 \mathrm{~mm}$, to get high corrosion resistance under high temperature and solve the match problem of welding material. The compound in the coating (marble, silicate, $\mathrm{Tio}_{3}, \mathrm{CaF}_{2}$ and so on) can reduce splatter, blowhole and prevent the burning of the aluminized layer. The chemical composition of the deposited metal is shown in Table 2.

The main technological process:

Joint preparation — surface derosination — wash — surface cleaning — spray welding layer — assembly and tack welding — base layer welding — surface layer welding — thermal insulation after welding - inspection after welding

Table 2 The chemical composition of the deposited metal \%

\begin{tabular}{|c|c|c|c|c|c|c|c|}
\hline $\mathrm{C}$ & $\mathrm{Si}$ & $\mathrm{Mn}$ & $\mathrm{S}$ & $\mathrm{P}$ & $\mathrm{Cr}$ & $\mathrm{Ni}$ & Mo \\
\hline 0.10 & 0.46 & 0.17 & 0.011 & 0.023 & 23.00 & 12.65 & 2.22 \\
\hline
\end{tabular}

Joint preparation. Process the joint part into certain shape before welding to ensure the welding quality. Use facing machine to get a $\mathrm{V}$ type groove at the joint of the aluminized steel pipe, with the bevel angle of $60^{\circ} \sim 65^{\circ}$, truncated edge $1 \mathrm{~mm}$, joint gap around $3 \mathrm{~mm}$. Keep strict to the size and relative position when welding assembly.

\section{Surface treatment of the parts.}

Surface derosination. Wash the welding part and the adjacent part of the work piece with acetone and alcoholic solution to clean the oil contamination on the surface of the parts. 
Surface cleaning. Mechanical cleaning: use file, steel brush, steel wire wheel and coated abrasive to polish the welding part and the oxidizing material in its adjacent area.

Chemical etching: After mechanical cleaning, etch the groove surface and its adjacent area with $10 \% \sim 20 \%$ saltpeter solution to expose the aluminized layer and base structure.

Weld coating. (1) Before welding, coat both sides of the welding groove (the flange and the steel pipe surface) with whiting to prevent welding splatter, and guarantee the quality of the aluminized layer at both sides of the welding joint. ${ }^{[2]}$

(2) Coat the inner surface of the pipe joint with welding coat, the composition of this coat is shown in Table 3. This coat can affect the weld crater, prevent burn-off and make sure the melting zone at the back of the welding joint is well fused; Besides, under high temperature of welding, the chemical dopant decomposes very fast, produces active aluminium atoms which penetrate into the melting zone. This will compensate the aluminium burning loss of the aluminized layer in the melting zone at the back of the welding joint, and raise the high temperature oxidation resistance and corrosion resistance.

Table 3 The main composition of the coating

\begin{tabular}{|c|c|c|c|c|c|}
\hline $\begin{array}{c}\text { Al2O3 } \\
(\%)\end{array}$ & $\begin{array}{c}\text { Al powder } \\
(\%)\end{array}$ & NaF (\%) & KHF2 (\%) & $\begin{array}{c}\mathrm{NH} 4 \mathrm{Cl} \\
(\%)\end{array}$ & $\begin{array}{c}\text { activator } \\
(\%)\end{array}$ \\
\hline allowance & $17 \sim 21$ & $0.8 \sim 1.2$ & $0.05 \sim 0.15$ & $0.1 \sim 0.2$ & $\begin{array}{c}\text { Reasonable } \\
\text { amount }\end{array}$ \\
\hline
\end{tabular}

Assembly and tack welding. Assemble the flange and the steel pipe together according to the designed requirement, and perform tack welding. Welding current should be $10 \% \sim 15 \%$ smaller than usual, the tacked spot should be as small as possible. No knocking after tack welding.

Welding. Adopt TIG welding, choose austenite welding wire, which has high crack resistance and can ensure good plasticity and tenacity ${ }^{[3]}$, the welding code is shown in Table 4.

Table 4 the welding code of the TIG welding of the Aluminized steel pipe

\begin{tabular}{|c|c|c|c|c|}
\hline $\begin{array}{c}\text { Welding } \\
\text { piece }\end{array}$ & $\begin{array}{c}\text { Diameter of } \\
\text { the tungsten } \\
\text { wire }(\mathrm{mm})\end{array}$ & $\begin{array}{c}\text { Welding } \\
\text { current }(\mathrm{A})\end{array}$ & $\begin{array}{c}\text { Argon flow } \\
(\mathrm{l} / \mathrm{min})\end{array}$ & $\begin{array}{c}\text { Power } \\
\text { polarity }\end{array}$ \\
\hline $\begin{array}{c}\text { Cr5Mo } \\
\text { aluminized } \\
\text { steel pipe }\end{array}$ & $\phi 4$ & $100 \sim 120$ & $8 \sim 10$ & DCSP \\
\hline
\end{tabular}

The base layer and surface layer should be welded separately. When welding the base layer, choose the lower limit of the welding current in table 4, and carefully watch the moving direction of the weld crater to make sure the metal of the welding joint and the penetrating layer at both sides fuse completely. Control the size of the weld crater strictly to prevent lack of fusion at the back of the welding joint, and watch out for the argon protective effect, no airflow distraction in the welding place. When welding the surface layer, make sure the weld pass is smooth and beautiful, no undercut exist at both sides. Do not start arc at the surface of the aluminized steel pipe when welding, avoiding burning of the aluminized layer.

After-weld treatment. After welding, wrap up the welding part with asbestos cloth as soon as possible to cool down slowly, preventing the hardened structure from turning up, especially the CrMo aluminized steel.

\section{After-weld inspection}

(1) Mechanical property test of the welding joint. The stretch test of the welding joint should be performed according to GB2651-89; the bend test should be performed according to GB2653-89. $\sigma b=558.327 \mathrm{Mpa}$,after bend test $\left(180^{\circ}\right)$, no crack produced, which proved that the strength and plasticity of the welding joint met the requirement.

(2) The inspection of the welding defect adopted the ultrasonic detection method, no crack and 
slag inclusion in the welding joint, and the quantity of the blow hole met the standard.

(3) The corrosion resistance test should performed according to GB151-1999, each item met the standard. As to the steel pipe joint, soak test should be performed in 30\% HNO3 solution and $3 \% \mathrm{NaCl}$ solution separately. After 180 hour soaking in etchant solution, welding zone remain its original appearance, metallographical test proves that the aluminized layer is in good condition.

\section{Conclusion}

The experiments prove that, when welding aluminized steel, TIG welding technology can be adopted by choosing austenite welding wire with reasonable welding process. Welding joint with good mechanical property and corrosion resistance can be achieved, and can meet the quality requirement. Therefore, Cr5Mo aluminized steel, with stable and reliable welding property, has very good application prospect.

\section{Reference}

[1] Liu Xintian, Surface Engineering, Kaifeng, Henan University Press, 2000.

[2] Wang Min, Welding methods of aluminized steel pipe [J], Tool \& Equipment and Engineering 2003 (153): 47-48.

[3] Xu Binshi, Surface engineering and Maintenance, Beijing, Mechanical Industry Press, 1996.

[4] Li Yajiang, Welding of the special and hard-to-weld material, Beijing, Chemical Press, 2004. 